\title{
EL GRAN MILAGRO... TODAVÍA
}

\author{
The Great Miracle... As Yet
}

\section{Paquita Suárez Coalla}

degrullos@gmail.com

The City University of New York - Estados Unidos

Recibido: 01-02-2017

Aceptado: 24-04-2017

\section{Resumen}

Este texto plantea una reflexión personal sobre las múltiples contradicciones y desafíos que la institución y la experiencia de la maternidad plantean a las mujeres, considerando un contexto muy específico: la academia norteamericana, a la que llegué como inmigrante privilegiada desde España. Si la práctica de la co-maternidad aparece en ciertos discursos como garante de la solidaridad entre las mujeres, otros factores como la raza, la clase o las puras circunstancias individuales, modulan nuestras vidas como mujeres, trabajadoras y madres. En cualquier caso, en nuestras sociedades desarrolladas e hiper-competitivas, solo gracias a las redes de apoyo formales o informales entre mujeres y a una voluntad decidida de involucrare en la crianza de $1 @ \mathrm{~s}$ hij@s por parte de nuestras parejas garantiza que la experiencia de ser madres pueda ser vivida como un gran milagro.

Palabras Clave: (Co-)maternidad, emigración, clase, raza, conciliación.

\begin{abstract}
This text proposes a personal reflection on the multiple contradictions and challenges that the institution and the experience of motherhood pose to women, considering a very specific context: the American academy, to which I arrived as a (privileged) immigrant from Spain. If the practice of co-motherhood appears in certain contexts as a guarantee of solidarity among women, other factors such as race, class or purely individual circumstances modulate our lives as women, workers and mothers. In any case, in our developed and hyper-competitive societies, it is only thanks to formal or informal networks of support between women and a clear will on the part of our partners that allows us to live the experience of motherhood as a great miracle.
\end{abstract}

Keywords: (Co-)motherhood, emigration, class, race, conciliation. 


\section{Nota Aclaratoria}

En un artículo de opinión publicado en el suplemento dominical del New York Times del 27 de noviembre del 2016, Shanti Sekaran, profesor de escritura creativa en el California College of the Arts, explicaba las ventajas de haber sido un emigrante privilegiado en los Estados Unidos, y comentaba cómo su estilo de vida americano dependía fundamentalmente del estilo de vida americano de Mario, el trabajador mexicano que les arregla a él y a su familia el jardín, les recoge la basura, les pinta las habitaciones y les ayuda con el mantenimiento de una casa que él, profesor universitario, no puede mantener. "My immigrant family's comfort is built on the work of other immigrants" dice Sekaran (2016) en este artículo titulado "Privileged Immigrant," y sus reflexiones se suman a otras reflexiones que han surgido inmediatamente después de que Donald Trump sorprendiera a una cierta parte de los estadounidenses el 8 de noviembre cuando se supo que, a pesar de un discurso que sobrepasaba con creces los límites de lo políticamente correcto, había ganado la presidencia de Estados Unidos.

Es cierto que, en el actual contexto estadounidense, son muchos los intelectuales que se han visto urgentemente forzados a reflexionar en voz alta sobre una situación que no es nueva pero que querrían creer superada tal vez para no cuestionar la comodidad material que -siguiendo el guion del sueño americano- habían alcanzado y para convencerse de que realmente este país en el que viven es el país de las oportunidades. No me refiero al ensayo de Sekaran, que me parece muy lúcido, sino más bien a las sorprendentes reacciones de sorpresa que he podido reconocer en mucha gente que parecía no haberse enterado de que el racismo, el sexismo y sobre todo el clasismo, seguía vertebrando los sentimientos profundos de una parte importante de la población de Estados Unidos. Se agradece como quiera -y qué triste que haya tenido que ganar Donald Trump para poder hacerlo- la actualización de estos discursos menos complacientes, pero ya en los años 80, la antropóloga Ellen Dissanayakee, que pasó gran parte de su vida estudiando en países no occidentales -Sri Lanka, Nigeria, Papúa Nueva Guinea-, alejada del mundo académico y del estímulo intelectual que este ambiente hubiera podido proporcionarle, reconoce en su libro What is the art for?, en un gesto genuino de humildad, la inapreciable ayuda de A. Margaret, la asistenta que tuvo cuando vivía en Sri Lanka y que se encargaba de toda una serie de tareas que, según Dissanayakee, los hombres dan por sentado cuando son sus mujeres quienes las hacen. "I owe a great deal to her and more than I like to admit to the inequities of a world in which because she and those like her have never had the opportunity to learn to read, I am permitted to have time to write" (Dissanayakee, 2002: XV).

Aunque procedo del mundo académico, y he desarrollado toda mi carrera en el ámbito universitario, me gusta pensar en la enorme influencia que mis orígenes campesinos y obreros han tenido en mi vida personal y profesional y cómo siempre me han servido de norte para 
cuestionar la validez de ese mundo elitista que se ha empeñado en secuestrarse a sí mismo y que poco ha servido para llegar a aquellos que procedemos de los márgenes y que por decisión, citando una vez más a bell hooks, decidimos no acercarnos demasiado al centro. Hablo por supuesto del elitismo de la academia, y de ese lenguaje oscuro que ha desarrollado para confundirse y confundirnos. Hablo también en primera persona, y no espero que nadie comparta mi frustración con el cúmulo de discursos vacíos que en su día leí con fe para llegar a la conclusión de que su aporte al más profundo conocimiento de los seres humanos -que es lo que a fin de cuentas busco y me interesa- era nulo.

Hace muchos años que he renunciado conscientemente a hacer ese tipo de crítica literaria que se piensa que cojea si no se disfraza con metalenguajes incomprensibles e inútiles, que tiene que sustentar todo en teorías que la alejan de la realidad que analiza, y que le da vueltas al lenguaje para esconder su falta de contenido. Una vez más quiero pensar que son mis orígenes campesinos los que me guían en esta visión del mundo más práctica, que persigue el significado real de las cosas y que desconfía de esos productos excesivamente disfrazados. En mi casa, donde siempre comimos las cosas que mis padres y abuelos cultivaban, y donde habíamos criado con todo el amor que se les puede tener a los animales que luego sacrificábamos para alimentarnos, usábamos un vocabulario básico y directo para explicar nuestra realidad, y cuando ese vocabulario no nos alcanzaba, porque la realidad se sobreponía a los términos lingüísticos, recuerdo que mi padre recurría a comparaciones y parábolas que parecían haber sido sacadas de la Biblia. Admiro a quienes puedan hacerlo, pero no es mi caso, y por eso no puedo teorizar sobre la situación de las mujeres minorizadas y marginadas sin contar sus historias. No me sale de otra manera, ni me interesa hacerlo y creo que la fuerza de lo que yo quiero decir, la consigo mejor de esta forma.

Ya en los años 70 Gloria Anzaldúa, a quien el tiempo ha convertido en referente de los estudios de género en las universidades estadounidenses, hablaba de su vida personal y de la vida de la comunidad chicana a la que pertenecía para formular sus teorías feministas. Angela Davis, una de las principales representantes del movimiento de las Panteras Negras explicaba al comienzo de sus memorias (Davis, 1974) que lo personal y privado es político, y Assata Shakur (1987), otra líder, hasta el presente perseguida de las Panteras Negras, a quien con la solidaridad que le caracteriza le dio refugio el gobierno cubano cuando consiguió escapar de la cárcel, contó todo el movimiento de lucha por los derechos civiles de los años 60 en una de las biografías más emotivas y profundas que he leído.

Como decía Audre Lorde (2007), no se puede deshacer la casa del amo con las herramientas del amo, y no voy a ser yo la que me refugie en teorías en las que no creo para contar la historia de mi madre, mis abuelas, mis tías y las mujeres que mientras yo iba a dar clases a la universidad y le robaba un tiempo al tiempo que debía dedicar a las obligaciones por las que me pagaban para escribir una historia, me cuidaron a mis hijas. Con todas ellas, de las que la academia apenas ha hablado, es con las que me identifico. 
A todas las mujeres que me acompañaron y ayudaron en este camino de la maternidad

A mis padres que vinieron cuantas veces les pedí de España

A mi suegra que llegó de Texas

A las niñeras que les robaron horas de atención a sus hijos para dedicarlas a las mías: a Sol, Fátima y Aracely

A Esteban que las llevó todos los fines de semanas al Museo de Historia Natural y al carrusel de Central Park mientras yo trabajaba, y que se levantó más de una noche con Jacinta porque quería escuchar música y que "la bailara"

$Y$, por supuesto, a Rosalba y a Jacin que me han dando tanto.

Sé, por supuesto que sé, todo lo que puede objetarse a esto, pero sigue pareciéndome un milagro contemplar un niño recién nacido, igual las niñas, ver esa figurita con ojos, nariz, boca, manos y pies con sus dedos correspondientes, y pensar que nueve meses atrás no existía sobre la tierra nada semejante a ella o él. A mí me parece milagro... todavía.

Sonia Rivera-Valdés

El 7 de noviembre del año 2000 me enteré de que estaba embarazada. Aunque la regla se me había retrasado ligeramente, yo estaba convencida de que aquellas dos últimas semanas que había pasado en hospitales y clínicas, tratando de averiguar si tenía un tumor cerebral, un aneurisma o un angioma, se relacionaban directamente con ese retraso. Así se lo dije a la ginecóloga cuando le expliqué por qué me había visto obligada a cancelar la cita que tenía con ella el mismo día que amanecí en el hospital de Hoboken, después de una noche incómoda paseándome en camilla de la sala de urgencias a la sala de escáneres, y de tener que volver al hospital de Jersey City a seguir haciendo pruebas cuando, ya con el parte de alta en la mano, alguien volvió a revisar mi expediente y decidió que algo seguía sin aclarar. La ginecóloga me dejó un poco con la palabra en la boca mientras se concentraba en la revisión que yo había ido a hacer y no habían pasado ni dos minutos cuando me dijo que tenía todos los síntomas de un embarazo. Yo seguí sus órdenes automáticamente al explicarme que me haría un test de orina, y mientras esperaba los resultados del test en aquel cuartucho con las paredes de color rosado donde apenas había espacio para las dos personas de rigor que lo tenían que ocupar, sentí que había anestesiado cualquier síntoma emocional que pudiera relacionarse con la increíble noticia que estaban a punto de darme. Me suele pasar, y estoy segura de que me pasó también esa vez porque no fue hasta que salí de la clínica que reconocí físicamente cómo las emociones iban rompiendo aquel estado de aparente indiferencia inicial. Entonces me fijé en la asombrosa claridad que las luces le daban a la oscuridad anticipada de las tardes de noviembre, saqué unas monedas de la cartera para llamar por teléfono a Esteban y darle la noticia, y empecé a caminar justo en la dirección contraria a la 
estación del metro. En el momento en el que me di cuenta de que estaba llegando a Columbus Circle, y me había ido alejando cada vez más de la entrada de la línea D que me llevaría a la 34 para coger el path para Hoboken, me di tranquilamente la vuelta y empecé a rehacer el camino. La sensación habitual de tener que llegar a tiempo había desaparecido y me arropaba en cambio una impresión inexplicable de atemporalidad. No pensaba en nada, abrumada como estaba al fin por los sentimientos, y hasta me había olvidado felizmente de la pregunta que me había salido de la boca como arrojada por el miedo cuando, no hacía ni siquiera una hora, la doctora había confirmado mi embarazo.

-El due date es el 12 de julio, me dijo después de hacer un cálculo rápido en un calendario circular que sacó de uno de los cajones de aquel armario empotrado a la fuerza sobre una de esas paredes irregulares de las oficinas de Nueva York, y de aproximar la aguja de plástico a la fecha que indicaba la última vez que había tenido la regla. Algunas otras veces haría yo esa misma operación matemática, con un calculador semejante que acabaría encontrado en internet, anticipando embarazos que solo un par de veces más se cumplieron, y jugando siempre con la idea de volver a ser madre.

No podré ir con los estudiantes al programa en España, pensé inmediatamente con un mal sentimiento de responsabilidad. O quizás sí-me dije a continuación para resolver ese sentimiento que ya me incomodaba- si el parto se adelanta quince días. Tal vez me acordé en ese instante de una de las compañeras del departamento que dos años antes había ido a trabajar a las dos semanas de dar a luz porque hacía apenas un semestre que había sido contratada y se sentía en la obligación de demostrar su profesionalidad por encima del bebé que empezaría a reclamarla cada dos o tres horas para darle de mamar, dormirlo, cambiarle los pañales y mostrarle su seguridad y afecto. La coordinadora de español, una mujer de origen irlandés que nunca había tenido hijos y que vivía en Staten Island, nos había pedido a algunos profesores que le cubriéramos entre todos una semana de clases para que ella pudiera estar con el bebé, aceptando como un hecho natural la decisión de nuestra compañera de incorporarse al trabajo a los ocho días de dar a luz, y ocultándole el derecho que tenía a quedarse con su hijo las seis semanas que a finales de los noventa nos quitaban de los días de baja por enfermedad porque la baja por maternidad aún tardaría años en negociarse y formar parte de nuestro contrato. Nuestra compañera había ido incluso a una comadrona para pedirle que le provocara el parto y hacer que el nacimiento de su hijo coincidiera con las vacaciones que solemos tener a principios del otoño durante las fiestas judías. La comadrona adelantó el nacimiento del niño y de esta forma, gracias a su intervención y a la generosidad de las profesoras que la sustituimos en sus clases, fueron dos semanas completas las que nuestra compañera disfrutó con su bebé.

De ese miedo tuve que olvidarme a marchas forzadas cuando obstetras y neurólogos se pusieron de acuerdo al contemplar los riesgos reales de un embarazo amenazado por las pruebas que me habían hecho en el hospital de Hoboken la noche que desperté con la parte izquierda de la cara adormecida, y por las posibilidades de que en el momento del parto se produjera una hemorragia cerebral causada por el angioma que me habían descubierto. El miedo tuvo entonces 
más sentido y me dio fuerzas para poner en perspectiva la suma de incomodidades a las que nos enfrentamos las mujeres de las sociedades materialmente desarrolladas.

Creyendo, no sin razón, que yo hubiera podido hacer lo mismo, una profesora de italiano que llevaba más de cuarenta años en la institución me habló de la práctica cada vez más extendida entre las profesoras de este país de organizar la maternidad para dar a luz en el verano durante el periodo de vacaciones. Yo entendía el intento, pero me llamaba la atención ese afán por concebir los embarazos en plan agenda, calculando el momento exacto para ser madre y regulando hasta los días de la gestación para influir en el sexo de los hijos. Si concebías al bebé cuando empezabas a ovular saldría niño y ocurriría lo contrario si lo hacías cuando el ciclo de ovulación estuviera acabándose; por eso había que poner tanta atención a las prácticas amatorias para conseguir que los deseos de ser madre o padre de una niña o de un niño se vieran satisfechos. El comentario de la profesora de italiano, que no renunciaba al sarcasmo cuando hacía una valoración más bien amarga de su larga vida en los Estados Unidos, no me cogió de sorpresa, lo que me provocaba una enorme curiosidad era saber aproximadamente cuál sería el índice de éxito de esas maternidades por encargo que en muchos casos incluían también el parto por cesárea para que el destino natural no se interpusiera a la fecha de nacimiento. Aunque yo no pudiera ir con los estudiantes al programa de español que había organizado para el verano en España, tenía que mostrarme agradecida de que Jacinta fuera a nacer en julio y de que la casualidad, o el destino, fuera a dejarme tan bien como la profesional que se esperaba de mí. No hacía siquiera un año que me habían contratado como profesora a tiempo completo y era mucho lo que desde ese momento me tocaba demostrar.

El destino había querido también que no fuera en ese momento la única profesora embarazada en BMCC. Un miércoles a la tarde que teníamos reunión del Consejo de Facultad me encontré con Patricia Mathews, una profesora peruana que da clases de antropología en el departamento de Estudios Étnicos, con una barriga tan prominente como la que yo misma empezaba a exhibir. Aunque nos conocíamos de antes y habíamos coincidido en algunos comités y eventos de la escuela, fueron nuestras respectivas barrigas las que crearon el vínculo que hasta entonces no había existido. Enseguida me enteré por ella que había otra profesora de Educación Infantil que estaba embarazada y una instructora de tecnología que acababa de dar a luz.

Patricia tenía un instinto activista que yo, con más timidez para el liderazgo, secundé siempre. Su mayor preocupación a finales del semestre era saber quién iba a cuidar de nuestros hijos cuando tuviéramos que regresar a la escuela en el otoño, algo en lo que yo, como no queriendo anticipar situaciones que tendría que resolver, todavía no había pensado. Sugirió que nos reuniéramos las cuatro con la vicepresidenta -no recuerdo bien si Ruru estuvo en esa reuniónpara hacerle entender la importancia de abrir un daycare para las profesoras de BMCC que en su momento lo necesitaran. El daycare ya existía, pero solo para estudiantes y, según nosotras, ampliarlo un poco no tendría que ser un gran problema, especialmente si estábamos dispuestas, como estábamos, a pagar lo que nuestras alumnas no pagaban. La vicepresidenta, una mujer afroamericana que había dejado de enseñar matemáticas hacía más de treinta años para dedicarse 
a la administración, empezó a darnos lecciones de vida al vernos a las tres embarazadísimas, y a contarnos lo mucho que ella había llorado cuando, al poco de nacer su hijo, se preguntaba cómo iba a hacer para no desviarse del camino de éxito que una mujer negra como ella se había comprometido a seguir. No tardó en encontrar una niñera como la que auguraba que encontraríamos nosotras y su hijo -a quien educó también para triunfar- se había graduado hacía poco de la escuela de leyes de Harvard. La vicepresidenta nos miraba desde aquella silla de vicepresidenta en la que tal vez le habría costado sentarse, y a pesar de la proximidad física, de la sonrisa constante al borde de los dientes y de los consejos displicentes de la abuela que no tardaría en ser, dejaba claro que aquella conversación era unidireccional. Desde mi ingenuidad, acicateada seguramente por el ánimo de entonces de Patricia, yo me había hecho a la idea de que conseguiríamos no sé de qué forma que la guardería de BMCC abriera sus puertas no solo a nuestras estudiantes, que lo necesitaban tanto, sino a las profesoras que, aunque un poco menos, también les hacía falta. Nos veía ganando una batalla no solo para las que en ese momento estábamos a punto de ser madres por primera vez, sino a las muchas otras profesoras que después de nosotras decidieran tener hijos. Nadie nos había explicado todavía, y mucho menos la vicepresidenta, que eran cuestiones del sindicato por las que 1@s profesor@s de CUNY, ni siquiera pagando, podíamos llevar a nuestr@s hij@s a un daycare que se reservaba exclusivamente para las alumnas. No se nos dijo pero se nos sugirió que si pagar no era el problema, teníamos la enorme oferta de guarderías de la ciudad, y si esa oferta no se acomodaba al alcance económico de un sueldo de profesoras, tendríamos que encargarnos de resolver una situación a la que muchas otras mujeres y familias, antes que nosotras, le habían hecho frente.

El lema de la vicepresidenta era sobre todo directo y sencillo: si yo sufrí, si yo lo pasé mal, si yo superé con éxito bastantes más inconvenientes que muchos de los que se quejan tienen, cualquiera que se lo proponga puede hacerlo y es su responsabilidad si no lo consigue. Ella no estaba dispuesta a allanarle el camino a nadie, aunque pudiera, así que cuando salimos de aquella reunión tan aleccionadora sin tener muy claro -a pesar de su claridad- qué nos había querido decir, una por una regresaríamos al punto de partida desde el que, ya por separado, tendríamos que acomodarnos a una situación que se iría resolviendo mientras la vivíamos.

A la vuelta del verano nos dimos cuenta de que cada una de nosotras había llegado a soluciones personales en cierto modo parecidas. Yo había decidido importar a mi madre y a mi suegra de España y Texas respectivamente hasta que acabara el año escolar y nos fuéramos de vacaciones a Asturias. Los padres de Patricia habían venido de Perú por un tiempo y cuando les llegó la hora de regresar, sus suegros -que vivían en Boston-, empezaron a acercarse dos veces a la semana a Nueva York para que el cuidado adicional de Martín no quedara exclusivamente en manos de niñeras. Y Ruru contaba con la ayuda incondicional de sus padres, que vivían en New Jersey, y la atención ocasional de su hermana que no tenía hijos para ocuparse de Maia. Solo Gigi, la profesora de educación infantil que estaba casada con el dueño de una ferretería de la calle Chambers, justo enfrente de BMCC, había enviado a la niña a una de las guarderías de Tribeca que empezaban a proliferar por entonces. Aunque Patricia, Ruru, Gigi y yo llegaríamos 
a reunirnos alguna otra vez durante aquel primer año en el que celebrábamos la maternidad como si fuéramos nosotras las que la hubiéramos inventado, poco a poco se fue haciendo obvio que esta circunstancia, muy al contrario de lo que habíamos querido creer al principio, no solo no nos había unido demasiado, sino que habíamos regresado con naturalidad al punto anterior a nuestra condición de madres.

Una profesora de francés con la que compartía oficina fue la primera que me aconsejó que buscara una muchacha ecuatoriana para atender a Jacin. Son dulces y cariñosas, me dijo aquella mujer desafecta que no hubiera dudado en hacerse un aborto si alguien le hubiera dicho cuando estaba embarazada que tendría que cuidar de su hija hasta el día en el que alguna de las dos llegara a morirse porque estaba enferma. Aunque tenía casi 80 años, agradecía que le siguieran dando clases en el departamento para ignorar durante unas horas el destino que la vida le había brindado, aquella hija esquizofrénica -loca, como ella decía-, con la que más de una vez la escucharía discutir por teléfono y dejarla con la palabra en la boca cuando la desesperación la controlaba. Vicky tenía una estudiante venezolana que era babysitter y me puso en contacto con ella. Conocía a Millaray porque era una de las estudiantes más entusiastas de BMCC, y aunque no había tenido la oportunidad de darle clase, no hubo evento que yo organizara en el departamento al que Millaray no asistiera. La posibilidad de tenerla de niñera me daba ese tipo de tranquilidad que uno no conoce hasta que tiene hijos y tiene que empezar a resolver toda una serie de situaciones imprevistas de un momento a otro, pero Millaray trabajaba a tiempo completo y aunque en principio yo solo la necesitaba unas horas a la semana, no podía. Me recomendó a Sol, quien empezaría a ocuparse de Jacin a finales de abril del 2002, cuando mi madre, después de pasar tres meses en Nueva York con nosotros tuvo que regresar a España. Sol no hacía mucho que había llegado de Colombia con un hijo de siete años, Christian, y no había tenido mayor trabajo estable que la limpieza de una iglesia de la que se ocupaba dos o tres horas al día. También había cuidado algún niño, pero siempre de forma esporádica y sin una continuidad que le permitiera contar con un ingreso acorde a la continuidad de sus gastos. A Sol le tocó la peor transición de Jacinta, quien desde el día de su nacimiento no había estado en otras manos que en las de sus padres y abuelas, y a quien oía dar gritos desconsolados en los desconsolados brazos de Sol mientras me alejaba de la casa por el pasillo. Siempre que yo podía regresaba del trabajo primero, y siempre que pude le quité a Sol unas pocas horas de aquella ocupación tan precaria que yo le ofrecía y que tanto necesitaba. Al llegar junio y quedarme de vacaciones me despedí de Sol sin comprometerme con ella para septiembre, como si me acechara la certeza de que el periodo de crianza hubiera terminado, o tal vez porque quería distanciarme del sentimiento de contrariedad que me había producido dejar a la niña dando voces y llorando, y agarrándoseme con desesperación al cuello cada vez que tenía que irme. A finales de agosto, dos semanas antes del comienzo del año escolar, y de nuevo en Nueva York después de un verano en Asturias, me di cuenta de que no solo no tenía niñera para Jacinta, sino que no tenía un número de teléfono con el que comunicarme con Sol. Estaba segura de encontrarla en la iglesia donde limpiaba, y con una ingenuidad que solo se justifica cuando la guía, como era el caso, algún tipo de fe, me acerqué un día a la calle 34 en 
busca de la "iglesia". Entré en la primera que encontré en las cercanías de la 34 -donde no recuerdo que hubiera ninguna- y nada más hacerlo fuimos conscientes - porque también Esteban me había acompañado- de lo ridícula que resultaba aquella situación y me di la vuelta. No procedía preguntar si había allí una muchacha colombiana que se llamaba Sol que iba dos o tres veces a la semana a limpiar y a la que andábamos buscando porque necesitábamos que en menos de quince días empezara a cuidar a nuestra hija.

Sin que recuerde muy bien cómo, logré localizarla. Sol reapareció milagrosamente y vio cómo Jacin empezaba a hablar y a aficionarse a las aceitunas y al jamón serrano, que ella llamaba jamón de Pepe porque era mi padre el que se lo cortaba para comer en Grullos, mientras despreciaba aquellos purés desabridos que se resistía a tragar. Sobrevivimos un año más en el que conté con el apoyo ocasional de mi hermana, que se había venido a vivir con nosotros, y en el mes de junio, cuando ya había asimilado que las niñeras también podrían cuidar de mis hijas, intuí lo que iba a pasar en el otoño. Me alegré por Sol, porque le hacía muchísima falta, pero lamenté la suerte que íbamos a tener con las niñeras si no lograba sacrificarme económicamente y ofrecerles más horas.

Fue a mediados de junio cuando Sol empezó a trabajar con una familia del Upper East Side que quería llevarla a Martha's Vineyard durante los meses de vacaciones para que atendiera a una niña que acababan de tener. Se iba con ellos después de darle de comer a Jacin y pasaba la tarde entera con esa familia haciendo una serie de recados que nunca a mí se me ocurrió pedirles a mis niñeras que hicieran. Iba a correos a recogerles paquetes, les hacía alguna compra, se acercaba a las oficinas donde trabajaba el señor a entregarle los paquetes que había recogido en el correo, y no era hasta que acababa de hacer todo esto que iba a cuidar a la bebé. Parece que la madre era escritora y el marido tenía algún tipo de negocio que no le permitiría estar más que los fines de semana con su mujer y su hija. Cuando llegó la hora de que se fueran a Martha's Vineyard, no muchos días antes de nosotros viajar a España, lo hicieron en un avión privado en el que llevaron a Sol sin Christian, quien pasaría el verano en Queens con los abuelos que habían llegado de Colombia. A Sol le dolía la separación de su hijo y me lo comentó, pero no estaba en condiciones de protestar y no lo hizo. Y en realidad yo tampoco. Y por eso, a la vuelta de las vacaciones en septiembre la llamé inútilmente para confirmar lo que ya esperaba: la familia la había contratado a tiempo completo y me tocaba buscar niñera.

A Fátima la conocí a través de Patricia Mathews, quien supo de ella por Wafa, una estudiante marroquí que trabajaba ocasionalmente de niñera y que hablaba cuatro idiomas, español incluido, con fluidez. Wafa estaba en mi clase de literatura colonial y años más tarde me enteré por su amiga Rosa que se había ido a vivir a Marruecos, decisión que Rosa no aprobaba porque más o menos debía entender que cuando uno consigue llegar a los Estados Unidos -no importa en qué condiciones- ya se ha llegado a la meta y al final del viaje. A mediados de 2012, Wafa me escribió desde Granada, donde estaba viviendo y trabajando, y me invitaba a visitar esa ciudad que ella había adoptado como suya, con mi marido y las niñas. 
A Fátima la compartimos Patricia y yo por un tiempo, hasta que sus suegros decidieron hacerse cargo de buena parte de los gastos de Martin y lo metieron en la nursery school de Columbia University. Fátima, Rosa y los abuelos se turnaban para ir a recogerlo a la guardería durante la semana y se quedaban con él hasta que uno de sus padres llegaba a la casa. Nosotros no nos podíamos permitir la responsabilidad económica de una atención de este tipo, tampoco teníamos ningún familiar ni cercanamente lejos, como en el caso de los suegros de Patricia que vivían en Boston, y lo mismo a Esteban que a mí nos tocó correr del trabajo a la casa y de la casa al trabajo -salvo el mes que venían mis padres a visitarnos, y ocasionalmente mi suegra- hasta que las niñas fueron lo bastante grandes para moverse solas por Nueva York y quedarse sin nosotros en el apartamento. Para cuando eso empezó a pasar, Jacinta tenía casi catorce años y Rosalba once, pero ya la costumbre me había acelerado de tal manera que me costó trabajo reducir la velocidad. Nunca lamentaré el corre-corre que tuvimos que vivir, porque fue el precio que pagamos para pasar más tiempo con las niñas, que además me dieron tanto, pero hay momentos críticos en los que la suma de noches maldormidas y de faenas en todas partes medio-hechas agudizan el deseo inconfesable de que ya tus hijas acaben de crecer y, al igual que en las películas, como decía la escritora cubana Mylene Fernández, se hagan de un día a otros mayores.

Tendría poco más de dos meses Rosalba cuando Fátima empezó a trabajar cuatro días a la semana con la familia del Upper West Side con la que ya hacía más de dos años que estaba trabajando. Para suavizar la transición, pidió que la dejaran seguir cuidando a las niñas los viernes y nos presentó a Aracely, una mujer salvadoreña que se había dedicado a la música y a la recuperación del folklore tradicional en su país y que ahora se encargaba de atender dos horas diarias a una mujer puertorriqueña con Alzhéimer que vivía en un asilo. La señora era la madre de Sonia Manzano, una escritora y actriz que se había hecho famosa desempeñando el papel de María en Sesame Street y que algún día llegaríamos a conocer en alguno de los conciertos en los que participaba Aracely. Con Fátima, Jacinta había desarrollado un vocabulario llamativo para su edad, porque ella le hablaba como si fuera una persona mayor y luego Jacin nos resumía a su manera lo que Fátima le había contado. De esa manera fui hilvanando la historia de una mujer que había escapado de Argentina, dejando a dos hijos adolescentes con un padre siempre al borde de la abulia después de que un coche arrollara, y se diera a la fuga, a su hija mayor en la Avenida 9 de Julio. El día del accidente su hija entró en coma, y la niña murió abrazada a su madre cuando no había cumplido los veinte años. Cómo Fátima acabó en los Estados Unidos es otra historia relacionada seguramente con esa tristeza insoportable que iba tapizando con palabras, con el autoconvencimiento de que tenía que trabajar para mantener a la familia que había dejado en Buenos Aires, y cuya ausencia nunca tuvo en realidad precio, y con el destino que la estaba esperando: casarse con el marido de la amiga que la había invitado a pasar un tiempo con ella en Massachussets para atenuar el dolor de la hija muerta, después de que su amiga se muriera en otro accidente de tráfico en las carreteras heladas de Vermont al enfrentarse a la imprudencia de un conductor borracho que se apareció en el carril por donde ella y su marido circulaban. Fátima acabó casándose con él a los dos años, haciendo de la hija de su amiga la suya, y yéndose a vivir 
a un pueblo en las afueras de Boston. Después de la boda se fue, pero ya para entonces Aracely se ocupaba ella sola de las niñas.

El día que Aracely vino a casa a conocernos, yo sentí la misma resistencia que había experimentado la primera vez que tuve que dejar a Jacin con una persona desconocida. Me había pasado con Sol, con Fátima y con aquellas otras mujeres que se aparecían de un día a otro para quedarse con mis hijas si algo se complicaba en la vida de mis niñeras habituales y no podían venir. Cuando le abrí la puerta y vi entrar por ese pasillo oscuro de nuestro apartamento a una mujer grande envuelta en un montón de chaquetas y bufandas a pesar de las temperaturas aún agradables de finales del verano, con un gesto adusto que se me hizo curiosamente familiar, y con un acento centroamericano al que no estaba acostumbrada, me relajé y supe que le daría toda mi confianza para ocuparse de las niñas. No hacía apenas dos semanas que había venido a verme una señora correctísima -recomendada por una antigua compañera del departamento- que me repitió demasiadas veces cómo siempre llegaba diez o quince minutos antes de la hora al trabajo y que hablaba con una cadencia, para mi gusto, demasiado afectada. Yo sufría de mala gana que alguna de las niñeras se retrasara y me obligara a echar a correr una vez las oía meter la llave en la cerradura de la puerta, pero aquel interés exagerado de la mujer por subrayar su apego al orden tengo que reconocer que acabó por molestarme. También su amabilidad estudiada, sus modales de libro, sus esfuerzos obvios para disimular su acento dominicano y su falta de interés por la niña que tendría que cuidar. Me olvidé de ella nada más despedirla y contraté a Aracely. Al principio unas pocas horas a la semana, porque seguía enganchada a aquel horario de tarde-noche y sábados-domingos que creí que me iba a funcionar mejor de lo que en realidad me funcionó para pasar más tiempo entre Esteban y yo con Rosalba y Jacin, y ya muy pronto, cuando me di cuenta de que mi cansancio y mi constante resolver a medias las cosas en todas partes y todo el tiempo tenía un precio, decidí que viniera cuatro días a la semana para ver si corría un poco menos y hacía un poco más. Si lo hice no lo sé pero aprendí a no medir al milímetro los gastos que se relacionaran con las niñas y, sobre todo, a no escatimar con quienes tenían que acomodarse a la escasez de un salario a tiempo parcial como baby sitters.

Cuando Rosalba cumplió cinco años y empezó a la escuela, tuve que insistir para que Aracely cogiera un trabajo a tiempo completo que le ofrecía la hermana de Sarah. No le apetecía estar con una familia que no fuera latina y aunque el número de horas que atendía a las niñas había disminuido drásticamente, parecía que había decidido no darse por enterada. Esto me ponía a mí en una situación comprometida porque después de ocho años sentía que había llegado la hora de poderme librar de una carga económica importante si bien no quería hacerlo antes de asegurarme de la estabilidad de Aracely. El día que el esposo de Amy me llamó para preguntarme por ella y saber si la recomendábamos para cuidar de Sam, yo, que había recurrido a mi mejor inglés para convencerlo de su buena elección, creí que la misma alegría que esa llamada me había dado a mí la sentiría Aracely cuando se lo contara. No fue así exactamente, y el desinterés que mostró me sacó tanto de onda que me vi casi en la obligación de hacerle una descripción gráfica de lo que yo veía que le estaba esperando. 
—La mujer que atiendes se va a morir en cualquier momento y yo, la verdad, necesito reducir gastos.

Aracely fue tan cáustica como yo.

-Usted por mí no se preocupe -dijo- déjeme cuando le haga falta.

La escuché con cierta incomodidad y dejé de insistir.

-Ya veré cómo me arreglo.

Yo sospechaba que lo de cómo me arreglo no iba a ser inmediato, a no ser la oferta real de la hermana de Sarah que, en mi opinión, llegaba en el momento indicado, así que tuve que hacer un esfuerzo para ponerme en su lugar y entender aquella resistencia suya a aceptar un trabajo que no le apetecía hacer. En realidad, sí la entendía, además me alegraba saber que se encontraba cómoda con nosotros, pero la sensación de pánico que a mí me hubiera producido quedarme de un momento a otro sin un ingreso que me permitiera cubrir las necesidades más básicas me hubiera hecho incuestionable la aceptación de casi lo que fuera.

$\mathrm{O}$ al menos eso es lo que creo.

Empezó a cuidar a Samuel a principios de año y yo volví a acomodar mi horario a los horarios de las niñas. Esteban también lo ajustaría para entrar una hora más tarde y tener tiempo suficiente para dejar a Jacinta y a Rosi en el autobús escolar que llegaba oficialmente a las ocho y diez, pero que la mayoría de las veces no aparecía hasta a y veinticinco o a y media. Yo me encargaba de recogerlas a la tarde, y tenía que salir corriendo de la facultad si quería llegar a la parada antes de que el autobús lo hiciera. Siempre llegué, pero los retrasos frecuentes de los metros me obligaban a controlar sin ningún éxito la enorme ansiedad que esas situaciones me producían. A Aracely seguimos llamándola ocasionalmente, más que nada por no romper los vínculos que más que con ninguna otra niñera habíamos creado, y porque en alguna ocasión queríamos salir a cenar, a tomar unas cervezas o a ver una película, aunque lo de la película es un decir que casi no fue salvo cuando hubo un estreno de Almodóvar que yo nunca perdoné porque el coste total de esa noche de cine sin copas y sin cena no bajaba de los cien dólares y, cuando además llegábamos a Washington Heights era tan tarde para que Aracely regresara desde el Alto Manhattan a la zona de Brooklyn donde vivía que se quedaba a dormir en la casa. Por eso nos aficionamos a los restaurantes del barrio que suplían la calidad del menú con la tranquilidad de la cercanía y el lujo de estar juntos dos horas completas.

Para ese entonces, después de casi una década en la que las nociones temporales de velocidad y lentitud se habían sentido de manera simultánea, mi relación con todas aquellas madres con las que compartí mi recién estrenada maternidad se había diluido tanto que quedó reducida a una amistad de pasillo. Nos saludábamos con entusiasmo cuando nos encontrábamos, y nos poníamos al día con los niños, hablando de las escuelas a las que iban y de los intereses extracurriculares que la mayoría de las familias modernas nos convencemos que tienen. Ya poco nos acordábamos de aquel activismo tan frágil de nuestra etapa de embarazadas ni de aquel interés que pronto tuvimos que ignorar para que se nos hiciera un hueco a las profesoras en el daycare de las 
estudiantes. Al cabo vivíamos en el país donde se exalta por encima de cualquier cosa el esfuerzo individual, y es muy posible que alguna de nosotras se sintiera triunfante por haber logrado lo que nos pronosticaba la vicepresidenta de la Facultad el día que fuimos a verla. Hubiera sido fácil adivinar desde el principio, al menos en líneas generales, el camino que cada una de nosotras acabaría siguiendo, pero tengo que reconocer que yo sí había querido creer que iba a ser de otra manera: que íbamos a conseguir que la vicepresidenta nos ofreciera ese espacio para nuestros hijos en la guardería de nuestras estudiantes, que íbamos a compartir niñeras para ahorrar gastos, y que íbamos a mandarlos a las mismas escuelas y seguir usando los mismos métodos de crianza de quienes habían dormido con sus hijos a conciencia y les habían dado de mamar a demanda. Quince años después, me sorprende un poco tanta ingenuidad y entiendo lo que entonces solamente sentía: que no fue hasta que las niñas nacieron y las eché a andar que yo reconocí mi condición de emigrante.

No sé cómo no me di cuenta ya de esto aquel otro día de otoño que organizamos una reunión de bebés y madres en la Facultad y, nada más llegar, me preguntaron qué libro de crianza estaba usando. Ante la cara de desconcierto que debí poner, ignoraron a la misma velocidad a la que hicieron la pregunta una respuesta que nunca llegué a darles, y empezaron a distribuir una serie de copias de un libro de referencia del Dr. Sears en el que enfatizaba los enormes beneficios del co-sleeping. Dormir con un recién nacido nos parecía a mi esposo y a mí una cosa bastante normal, de la que ni siquiera habíamos hablado cuando iba a nacer Jacinta, pero reconozco que me alegré cuando ese día descubrí que la ciencia respaldaba nuestras intuiciones. O una parte de la ciencia, porque había libros para todos los gustos y para que nadie se sintiera culpable si deseaba encerrar a su hijo en una habitación propia desde el primer día para que se fuera acostumbrando; a qué exactamente no sé, pero supongo que a no molestar. Una vez distribuyeron las copias, llegaron explicaciones y comentarios, y con el espíritu de supervivencia de quien se siente fuera de lugar, debí de dar gracias por haberme encontrado con esas madres que seguían justamente las lecturas que recomendaban la forma de crianza que yo estaba haciendo. Como me diría una amiga española al verme amamantando a Jacinta cuando ya tenía casi dos años, éramos un grupo de madres modernas que estaba criando la siguiente generación de gente feliz. El entusiasmo compartido no superó siquiera el periodo en el que nuestros hijos empezaron a dar los primeros pasos y a salirles los primeros dientes. Y ese periodo aparece registrado en otra reunión que hicimos a finales del año escolar, cuando ya empezaba a hacer calor y más que nada pensábamos en el verano, y fuimos a comer a un restaurante cerca de la Facultad que tenía un espacio afuera para los carritos de los niños y otro adentro para que madres y padres los dejaran correr a su gusto, sin preocuparse por su seguridad y sin preocuparse sobre todo por las molestias que pudieran causar a otros clientes. Allí pedimos unas sopas carísimas con nombres étnicos que, para no sentirme fuera de lugar, hasta yo misma celebré con mi inglés despersonalizado y al despedirnos, deseándonos unas a otras el mejor de los veranos, yo sentí con cierto alivio que aquella iba a ser nuestra última reunión.

Lo fue. 
Y a partir de entonces, nos conformamos con esos encuentros espaciados por los pasillos que nos alcanzaban para resumir los puntos sobresalientes de nuestras historias.

Una de ellas se mudaría a los suburbios cuando se quedó embarazada por segunda vez porque quería tener más espacio y poder ofrecerles a sus hijos una vida teóricamente más tranquila que la que vivíamos en Nueva York. Para convencerla, porque debió de costarle renunciar a su trabajo académico y dedicarse únicamente al cuidado de los niños, se dijo que su esposo le regaló un anillo de cinco mil dólares. Alguna de las otras madres suspiró por ese anillo que nunca lograría tener, y aún es el día de hoy que yo me pregunto, cada vez que me viene a la memoria, cuál puede ser la satisfacción de cualquier persona de lucir en sus manos un anillo de ese precio. Otras cambiarían las niñeras del primer año por guarderías de élite que aseguraran, cuando llegara el momento, poder enviar a sus hijas a la mejor escuela pública de la ciudad que, a su vez, les permitiera en su día el acceso a la High School de más reputación y a una universidad a la misma altura: Harvard, Princeton o Yale, a ser posible. También cuando llegó el momento hubo quien se cambió de barrio o quien buscó la manera, sin llegar a hacer este movimiento imposible, de enviar a sus hijos a las escuelas de las comunidades con un poder adquisitivo superior al de las comunidades donde vivían. Algunas de estas mismas familias que desplazaron a sus hijos a esos barrios que les aseguraban una mejor educación, y un mejor grupo de amistades y relaciones, son las mismas que años después, cuando llegó la hora de hacer solicitudes para la universidad, escribieron ensayos reclamando la porción de latinidad que los hacía candidatos a las mejores becas para minorías aunque nunca sus hijos hubieran compartido un pupitre con los hijos de los que en realidad habían tenido una educación menos privilegiada y necesitaban realmente esa ayuda.

Por una serie de razones nosotros decidimos enviar a las niñas a las escuelas del barrio; la primera, y la más sensata, porque no teníamos tiempo para ir a llevarlas y a recogerlas a una escuela de Downtown, y queríamos aprovechar que ya no necesitaban niñeras para ahorrar el dinero que nunca iba a sobrarles cuando una vez en la universidad se volvieran a incrementar nuestros gastos; también porque yo carecía de estrategias y recursos para influir en el equipo administrativo que las podría aceptar en un distrito que no les correspondía pero, además, y en el fondo de todo, por un profundo sentimiento de identidad que me acercaba más a esas mujeres mexicanas, ecuatorianas, dominicanas o salvadoreñas que hablaban un inglés con acento como yo (muchas mejor que yo) que habían arriesgado sus vidas cruzando la frontera, algunas de ellas embarazadas o con niños pequeños, que les daban de mamar y dormían con ellos sin falta de que ningún libro de ningún súper experto se lo recordara, que a muchas de las mujeres profesionales con las que en teoría se supone que yo compartiera más cosas. Hubo ocasiones en las que tuve una especie de sensación de que los estudios universitarios que mis padres nos habían dado a mi hermana y a mí para que pudiéramos defendernos en la vida, como repetían que ellos no se habían podido defender, no me hubieran servido más que para conseguir un trabajo que me pagaba bien por hacer lo que me gustaba y vivir con una cierta holgura y comodidad material, tantas fueron las veces desde que las niñas empezaron a la escuela en las que sentí que no sabía navegar en una 
sociedad cuyas reglas ni acababa de entender ni compartía. Volver a casa, como cuando era pequeña, ponía un cierto orden a ese desajuste emocional que me provocaban las reuniones de padres, las celebraciones de cumpleaños, los playdates y la búsqueda desesperada de los mejores centros educativos cuando llegó la hora de salir del barrio y entrar en el mercado competitivo de una enseñanza pública que empieza un proceso de segregación cuando muy tarde a los once años. Por eso, ahora que ya las niñas son casi grandes -Jacinta cumplió quince años en julio, y Rosalba hizo trece en abril-confirmo a través de sus ojos que mi malestar no se debía únicamente a mis limitaciones de un código lingüístico. El rechazo lúcido de mis dos hijas a este modelo de sociedad que en nombre de un progreso que se contradice a sí mismo no nos deja vivir en paz sobre todo a las mujeres- con nuestros ritmos, nuestros cuerpos, nuestros deseos más íntimos y nuestras múltiples identidades concuerda con muchos de los desencuentros que desde que las niñas nacieron he ido experimentado, desencuentros a los que algunas veces supe poner nombre y otras no, que en ocasiones quise ignorar y otras no pude, y que al final de la carrera acabaron por dejarme, sin que eso me sorprendiera mucho, con las mismas mujeres con las que la había empezado.

O casi con las mismas, porque la presencia milagrosa de Rosalba y Jacin en mi vida, en cada uno de los días que ahora componen mi vida, es una circunstancia demasiado grande para, por encima de cualquier otra, no celebrarla.

\section{BIBLIOGRAFÍA}

- Davis, Angela (1974): An Autobiography. New York: International Publishers.

- Dissanayake, Ellen [1988] (2002): What is Art For? 50ª Edición. Washington: University of Washington Press.

- Lorde, Audre [1984] (2007): Sister Outsider. New York: Crossing Press.

- Sekaran, Shanthi (2016): “The Privileged Immigrant”. En: The New York Times, 26 de noviembre de 2016. Disponible en: https://www.nytimes.com/2016/11/26/opinion/sunday/theprivileged-immigrant.html?_r=0 [20/01/2017].

- Shakur, Assata (1987): An Autobiography. Westport, CT: Lawrence Hill and Company. 